\title{
Academic Advising and Video Games: A Phenomenological Analysis
}

\author{
Zack Underwood \\ Virginia Tech
}

\author{
Helene Goetz \\ Virginia Tech
}

\begin{abstract}
This article examines video games and their influence on one particular career field: academic advising. The authors define video games, learning from video games, academic advising, and the connection between the two fields in a phenomenological lens. With the popularity of video games and the field of academic advising, there are many similarities, influences, and lessons to explore. This article examines broader practical and metaphorical connections between the popular media of video games and interactions within the workspace of academic advising.
\end{abstract}

Keywords: academic advising, video games, connections, theory

\section{INTRODUCTION}

Learning in the workplace occurs in a variety of contexts, both through formal training and education and through outside learning and experiences. As job requirements evolve, organizations face "potential challenges, particularly for knowledge management, skills update and skills obsolescence" (Ypsilanti, Vivas, Räisänen, Viitala, Ijäs, \& Ropes, 2014). While employers typically focus on traditional professional development methods, employees also grow skills from personal experiences outside of the workplace: through volunteer activities, hobbies, parenting and even through video games. "People play [video games] everywhere" and as a result influences our lives (MacKay, 2013, para. 12). Video games influence life.

Though not generally linked to careers, video games influence the way in which individuals approach life, learning and how to work. Video games have infiltrated pop culture, our homes, and our workplaces. The Entertainment Software Association (ESA) (2020) establishes that "214 million people in the United States today play video games one hour or more per week" (para. 3). Video games are unique because players can "seek out new experiences and absorb new knowledge about the world - and ourselves. They provide a safe place where we can relax as digital tourists," a medium "offering scientists... a way to explore and understand what it means to be human" (Etchells, 2019, p. 268). This means that video games can influence individuals differently including potential for skill-building, practicing in a virtual environment, and learning about life in general.

When viewed from a holistic learning viewpoint, video games are not a disconnected escape, but directly influence the player by developing skills useful in work and life (del Blanco, et. al, 2012). "Playing games to support learning is a classic concept that is seeing a revival today" (Wiklund \& Mozelius, 2013, p. 290). Video game play is linked to improved cognition, increased motivation, adaptation from feedback, 
design thinking and job skills (Eichenbaum, Bavelier, \& Green, 2014; Tannahill, Tissington, \& Senior, 2012). Video games are learning tools that can influence more than just pop culture.

This article is a phenomenological examination of video games and their influence on a particular career field of academic advising. The discussion to follow will establish foundations of video games including definitions, examples, and guiding principles linking video games with learning. Academic Advising as a field will also be defined and explored. This overview leads to a comparison of the two fields and an outline of future directions for research.

\section{DEFINING VIDEO GAMES}

An initial definition of a video game should start with the word "game". "A game is an intersubjective social process made meaningful by its participants, fundamentally rooted in material reality" (Montola, 2012, p. 314). Adding video elements such as a monitor or tv adds to the experience and expands a game to a video game. "[A videogame is] a mode of interaction between a player, a machine with an electronic visual display, and possibly other players, that is mediated by a meaningful fictional context, and sustained by an emotional attachment between the player and the outcomes of her actions with this fictional context (Bergonse, 2017, 253). Unlike film or radio, video games require the player to interact with the media. "Players cannot passively surrender to a game's storyline" as with a film, they must take action (Granic, Lobel, \& Engels, 2014, p. 67). This sets video games apart from other passive media such as television or film.

For the purposes of this article, the term "video game" will refer to software for any video game hardware where there is interaction between the player and the machine. This definition of video game is deliberately broad to include games from a range of eras, from arcade machines such as Frogger or Asteroids to phone apps or home consoles such as Nintendo Switch, Playstation 5, or Xbox 1. The authors contend that individuals may have been influenced by gaming from a young age as much as academic advisors who play games today, and that older arcade machines or consoles can provide learning opportunities equal to modern gaming.

\section{DEFINING ACADEMIC ADVISING}

Academic Advising involves two parties, the academic advisor and the academic advisee. Academic advisors are professional faculty or staff members at colleges or universities whose responsibility either officially or unofficially is to navigate students towards graduation. Advisees are students at the institution whether undergraduate, graduate, or even non-degree seeking students. Advisees arrive from a variety of backgrounds and require guidance in achieving their individual academic goals.

Advisors utilize multi-dimensional thinking to help students progress by acknowledging students' identities, goals, backgrounds, and many other variables to help them make decisions (Grites, 2013 blue book). "Advising facilitates the development of meaning through engagement in experiences and interaction with others" (Kimball \& Campbell, 2013, p. 6). A simplified way of looking at academic advising is as a variety of teacher.

\section{ACADEMIC ADVISING AND LEARNING}

Academic advisors must develop teaching skills in the same way as instructors. Therefore, learning is key for advisors. Lowenstein (2005/2021) defines a learner-centered approach to academic advising where the advisor is a coach, akin to a teacher, to teach educational logic, connecting academic curriculum to larger framing, making decisions, and encouraging lifelong learning. In this sense advisors are teachers because they instill knowledge into advisees in a variety of ways.

NACADA (National Academic Advising Association) (2021) breaks advising down into three pillars, Conceptual, Informational, and Relational. The Conceptual pillar investigates the theoretical foundations, the why, and goals of advising in general of an institution. The Informational pillar examines data involved 
with advising, campus policies, procedures, and campus culture regarding specific student populations. The Relational pillar looks at the practicality of advising, how one goes about advising, relating to the student, communicating to students, and investigating advisees' academic scenarios (NACADA, 2021).

Advisors should be expected to continue as learners as well (Lowenstein, 2013). Advisors can gain insights from a variety of viewpoints to help them become better at their jobs. To learn, advisors should go through similar processes as their students. Reflecting on their experiences with playing video games and critical analysis of video games are examples of lifelong learning.

\section{VIDEO GAMES AND LEARNING}

The immersive nature of games can lead to skill-building directly through input such as behavioristic interactions or indirectly through theoretical connections such as recognizing patterns in games and work. However, not everyone may realize that learning is taking place. Papert (1998) described learning as "essentially hard; it happens best when one is deeply engaged in hard and challenging activities" (p. 2). Csikszentmihalyi (1997) would describe this same condition as "flow," a situation where players engage with material so intensely and with such focus that time passes by quickly with little attention to the outside world. Duggins (2019) asserts that "by more fully immersing students into the action of learning, rather than just the somewhat passive act of reading what we want them to learn, students become more engaged and take ownership of their knowledge" (p. 73). Recognizing that learning is taking place is a purposeful piece of video game literacy.

Video game literacy is defined as "having the ability to play games, having the ability to understand meanings with respect to games, and having the ability to make games. Each part of video game literacy is related to influences, and is influenced by the others." (Zagal, 2008, p. 34). Though referring to students, MacKay (2013) recognizes that individuals should play with a design mindset: as one who interacts with the game as well as thinking about the design decisions from game creators to recognize learning. Practicing and playing expands understanding of the game. In a similar scenario, owning a car does not make one a good driver. In regards to driving, comprehending road layout, traffic, driving skills, patterns in driver behavior, and memorization is key to being a better driver. Understanding the contexts, practicing, and recognizing learning opportunities is at the heart of video game literacy. With video games, the media influences the user or player.

Video game literacy involves the act of pointing out skill building and knowledge growth influenced or gained through video games. "Video games can help people see better, learn more quickly, develop greater mental focus, become more spatially aware, estimate more accurately and even multitask more effectively" (Fleming, 2013, para. 4). In a more philosophical sense, "the significance of the video game lies in the way that it makes use of and encourages a particular epistemological approach to space" (Fraser, 2011, p. 94). McHaney (2011) makes the argument that millennial students "learned complex materials, practiced actions, and experienced decision making in the context of simulated situations" towards active learning (p. 60). The idea is that video games can influence the way not only students, but advisors see the world cognitively, physically, and even psychologically.

The act of playing can also promote skill-building. Researchers have determined that even tinkering with media, whether through play or creation of video games, can lend itself towards $21^{\text {st }}$ century skill growth (Qian \& Clark, 2016). Gee (2007) points out video games "situate meaning in a multimodal space through embodied experiences to solve problems and reflect on the intricacies of the design of imagined worlds and the design of both real and imagined social relationships and identities in the modern world" (p. 41). Video game players are able to embody avatars and make decisions outside of the realities of real-life. This lends to many possibilities for learning and connections to the workspace of academic advising.

\section{CONNECTIONS BETWEEN VIDEO GAMES AND ACADEMIC ADVISING}

"Games are identified as social spheres" (Härig, 2012,p.209). Games require a type of social interaction or decision from the individual. In this case, a button push or moving the virtual protagonist is a simple 
example of learning. At the simplest level this interaction is similar to behaviorism. The player makes a move and the computer or machine counters the move, providing feedback. Akin to Pavlov's slobbering dogs upon hearing a bell, the player recognizes an obstacle and reacts. For example, in Pong, a player sees a ball approaching their paddle and immediately must make a decision to move the paddle towards the path of the ball or remain still. Players receive feedback of hitting the ball with the familiar beep sound or miss the ball with a failure sound, then move to the next decision. However, learning is more complex than behaviorism. Similarly, academic advising involves more than just a behavioristic interaction of checking off boxes towards graduation.

From a phenomenological viewpoint, video games are phenomenon learning experiences unique to each individual. Both authors of this research are academic advisors and combined for a total of over 40 years of experience in the academic advising field. The following section examines four ways in which academic advising as a career field and video games overlap. "How we play games and the reasons we play them are different things: varying from person to person, game to game. They will even evolve as we play the same game" (Etchells, 2019, p.61). These are phenomenological observations in ways that video games interact with academic advising.

\section{Practice Makes Perfect}

The philosopher John Dewey (1934/2005) identified repetition as the road to learning. Actions and reactions to gaming death or taking damage causes the player to adapt. Socrates (399 BC/1997) explained that "no one knows whether death may not be the greatest of all blessings for a human being" (Cooper, a5). However, virtual death might be the greatest of all blessings due to the ability to learn from the mistake.

Far from representing failure, losing in a game can actually teach the player to adapt. Video games give the player motivation to continue by besting the last high score or reaching a new area that was previously out of reach. "Success, however illusive, never seems out of reach because the relatively low cost of failure brings the two concepts much closer together, making them less polar and absolute" (Tannahill, Tissington, $\&$ Senior, 2012, p. 3). The lack of success allows the player to feel a sense of control, even though they are not completely assured of winning due to variables within the game (Granic, Lobel, \& Engels, 2014). Similarly, academic advising does not prove successful every time an advisor meets with advisees, the adaptability from gaming can apply to advising situations.

Failure does not have the same consequences in video games as in real life. Failing a class in real life for example holds larger ramifications whereas failing in a video games is a low stakes mistake. According to the NACADA Core Competencies, practicing towards perfection is both an informational and relational competency because of conversations on policies or assessing failures in advising in general. There is always a chance of failure in conversations, emails, or citing policy. As they say, to err is human.

Practice also applies to learning student behavior through improved discussions and collaborative advising sessions. Knowledge is created by finding connections between cause and effect including accepting and valuing behavioral and environmental variables (Xyst, 2016). This means that academic advisors make split second decisions to share their own experiences or experiences from previous advising appointments with students. Human beings run possible scenarios through their head to make decisions. Over time and with practice, these decisions can improve thanks to feedback from students (Gee \& Gee, 2017). Advisors can make the decision to tell a student about the difficulty of a particular course or explain the consequences of making a certain GPA. These types of decisions lead to reactions from students and outcomes that may or may not be successful.

A simple example of this is the 1985 game Super Mario Bros. The game makers created Super Mario Bros with the idea that each player has 3 lives, not one life as in real life, which means that they assumed accidents would happen. Obstacles, including pits and enemies are potential areas of failure. Players often make mistakes by mistiming jumps or touching an enemy. From failure, players learn to adapt. "Humans are designed to steer through, adapt, persist, and overcome" (Baldwin, Bunting, Daugherty, Lewis, and Steenburgh, 2020, p. 21). Touching an enemy in one spot and dying leads to a memory for the player not to touch that enemy in the future. 
The consequence of dying in Super Mario Bros is that players reflect on that experience. If a player is struggling, they may consult a friend, or consult a walkthrough online to find the answer. Reflection in general, whether considering a video game or an advising session can lead to knowledge development. Speaking about failures can lead to learning by engaging in conversations or thinking about scenarios for improvement. Both authors have experience speaking with a faculty member, a partner, or fellow advisor about a failure. Practice in regards to advising can be explored through case studies or what if scenarios involved hypothetical advising issues.

With academic advising, mistakes are possible with every student. Academic advisors must make immediate decisions and answer multiple questions per advising appointment. A simple mistake like transposing a course number (for example, telling a student to take COMM 3124 instead COMM 3214) or misunderstanding a major as International Business when the student said International Relations, could be the difference between a student graduating on time or graduating a semester later. With advising caseloads of 250 students or more in some cases, an advisor might give a student a wrong form or even call them the wrong name.

Though mistakes can occur, moving on from the event is the key to success for academic advisors. Like a player avoiding that enemy in Super Mario Bros, the advisor must adapt. Each advising session is practice for future sessions with students who are pursuing a particular major. Advisors learn from each student and adapt to the needs of that student. Even though games are usually the same situation in each playthrough, real-life demands adapting to the student's needs and learning from mistakes through the maze of higher education.

\section{Cultural Navigation Through a Maze}

In research, advisors can be compared to cultural navigators. "Cultural navigators are those who know...codes of conduct, customs, dominant values, language, requirements, rules, and traditions" (Strayhorn, 2015, p. 59). The advisor is the professional and the knowledge holder. Knowledge can be shared in a prescriptive fashion, like a doctor, or as a guide in a developmental way. Students might refer to their academic advisor to find the answer to their questions.

Higher Education is a maze filled with hierarchy, vocabulary, acronyms, and bureaucracy. Students come from various backgrounds and may not have the same experiences or understanding of what college entails. Academic advisors serve as guides, helping students navigate both academics and college life. For example, a single referral to a campus resource or student organization might have a positive impact on a student's college experience. This aligns with all three of NACADA's competencies and has parallels with maze-related video games like Pacman.

Pacman was created in 1980 with multiple versions released since that time including Ms. Pacman, a Google Doodle Pacman, and most recently Pacman 99 on Nintendo Switch. Pacman is a classic game and one that many people can associate with because of the longevity of its popularity. This is also one of the authors' favorite video games because there are so many metaphors associated with the game.

Imagine advisees as Pacman and the advisor as the observer playing the game. The advisor is able to see the maze and everything going on within it, but the advisee is limited to a first person view with walls surrounding them. Students do not necessarily see the ghosts, the energy pellets, or that first exam in Chemistry that they might fail. The advisee's environment is a single path with options for diversions, opportunities, or failures. The advisor can help the student understand university acronyms, locate services on campus and complete required paperwork - ultimately avoiding the obstacles and finding the exit to graduation.

Common advising software can be strange or confusing to students. Advisors have the advantage of authority in certain situations that will help them to find answers faster than students. The advisor's role is to explain answers, possibly multiple times, to help students find their way to graduation, and guide them through the maze. Advisors have experience navigating course catalogs as well as university policies and procedures to find the exact answer for a student, or to refer them to university offices that would best suit a student's need. 
Both authors can recall moments where they knew the path a student should take and helped them to reach that goal. This might mean using encouragement to boost morale, helping a student improve poor GPA, having a longer than usual session to express to a student that their grades are not high enough to pursue their dream major, or helping a student rearrange her schedule to graduate in a timely fashion. As a cultural navigator, academic advisors have an advantage as well due to their own previous background or experiences throughout life that could also be relevant. Advisors can make the choice to share lessons through storytelling about past advisees or reflections from their own lives.

Advising is all about helping students to make new connections, which is a process of learning. "Humans can learn by associating cognitive concepts together, by creating new mental representations of concepts, and by creating cognitive maps of spatial arrangements" (Gentile \& Groves, 2014, p. 126). Each student's advising session requires full attention from the academic advisor. Advisors need to be attentive to the different backgrounds and experiences of students, which might include students beginning college for the first time or international students navigating a new language and culture. Even a small connection from a conversation to a larger issue can help a student to be successful or perhaps find a pattern that was not previously seen or recognized. For example, helping a student to recognize their lack of studying for a course could help them to establish healthy study habits in the future.

\section{Seeing Patterns}

One way to adapt to playing a game and to be a cultural navigator is to recognize patterns. Even though higher education is a maze, there are consistencies. "Through advising, students learn to distinguish the coherent patterns and systems of the institution and the ways they fit together. To do this, they must analyze the factual, conceptual, procedural, and meta-cognitive knowledge" (Mueleck, Smith \& Allen, 2014, p. 66). In order to teach students, advisors should be adept at identifying consistent patterns and fundamental processes of the institution.

As humans, individuals establish natural patterns over time due to past events or choices, these patterns can help advisors build best practices for the future (Gee \& Gee, 2017). Each institution and advising office experiences busier times and slower times. Natural ebbs and flows may follow the academic year or graduation timeline, but others could be unique to advising. Even conversations can follow patterns for students in distress, such as referring students who are struggling in classes to campus tutoring or referring students who are sick to health centers.

Seeing patterns is a natural idea for many retro gamers who played games in the 1980s and early 1990s. Since the player was engaging with a machine, there were natural limitations to early software leading to patterns. Arcade machines created with the purpose of taking players' quarters fed off of patterns. Galaga is a great example of patterns in games and in the advising world; patterns belong to NACADA'S Informational Competency.

Galaga is a top-down shooter meaning the player controls the plane at the bottom of the screen and shoots enemy planes at the top of the screen. At the start of each level, enemies enter the board in a loop. As levels progress, loops become faster and dodging missiles from enemy ships is key. Missiles fall in a pattern for each level. Once on the screen, each enemy attacks the player in patterns. The patterns are the same for each type of enemy. Red enemies go straight, blue enemies loop around before exiting the screen. Players can memorize when and where enemies arrive to know where to shoot and create strategies for eliminating all enemies on the screen. Other video game examples of patterns include Frogger, Dig Dug, Space Invaders, and many games created in the 1980s.

If students need to recognize patterns, then advisors should be the lead or guide for learning patterns for their advisees. Consistent patterns in advising include prescriptive information. "Advisors are generally comfortable drafting prescriptive instructions, pointing students in the right direction, helping them anticipate, and even delivering an occasional speech" (Champlin-Scharff and Hagen, 2013, p. 237). Examples of prescriptive information include common dates and deadlines related to advising such as the first day of class, the dates for course registration, and the last day to add or drop a course. Lowenstein (2013) believes pattern identification is key for learning for students. Advisors can learn this prescriptive 
information through many sources to prepare for frequently asked questions and prepare for each unique student's advising session much like a Galaga player anticipating the moves of incoming enemy ships.

\section{Identity and Embracing Differences}

As an academic advisor, it is important to approach each advising appointment and student as unique. Each academic advisor works with students from various backgrounds that include but are not limited to socioeconomics, place or country of origin, study skill levels, work or job experiences, genders, goals/aspirations, and more. "In order to figure out where someone is coming from, we need to try to see the world as he or she sees it. People do not act on the world as it is, but as they perceive and as they make sense of it" (McNamee, 2014, p. 86).

Virtual worlds in video games provide a framework for advisors to learn about others and experience the world through a new lens. "Video games are intrinsically motivating in part because they provide a context (albeit a virtual one) in which players can explore different aspects of their selves and 'try on' ideal characteristics" (Przybylski, Weinstein, Murayama, Lynch, and Ryan, 2012, p. 69 PWRPT). New connections can be made between virtual decisions and real life decisions, akin to a virtual sandbox. Gee and Gee (2017) describe the opportunity that games provide towards "a new world to probe and with which to have a conversation. And perhaps, these new conversations can teach us things about the real world, about language and learning, and perhaps about ourselves and our minds" (p. 10). With reflection, advisors can recognize identities in virtual worlds and how they relate to the real world.

Identities are a social construct that allows for flexibility (Cote, 2020). "Human learning is not just a result of brain working, but it is fully rooted in the material, social, and cultural context soil...humans learn, think, and solve problems by reflecting on their previous embodied experiences" (Zhang \& Shange, 2015, p. 405). With this in mind, video games are an opportunity for advisors to explore identities in a virtual environment as well as expand understandings of identities in the real world.

A sample video game that could exemplify this identity characteristic is Kratos of the God of War series for Playstation consoles. With nearly six different games, Kratos' story is the anti-protagonist at times. Kratos holds many identities including a soldier, a father, a widower, an enemy, a fighter, a thief, a person who attempted suicide, and a deep thinker. The player controls Kratos and could identify with the protagonist for all or none of the identities of the main character. However, playing as the main character could help the player to identify with different populations of people. As Kratos, the player must make decisions that could impact other characters in the game, for example to help an individual or to not help them. Similarly, advisors make decisions impacting others on a daily basis.

Academic advisors can make decisions in a virtual world that can help them communicate more efficiently and relate to their students. "Video games potentially help us to better understand how emotion and empathy is involved in ethical thinking and decision-making" (Schrier, 2016, p. 35). In certain video games, the player has the choice to play as a good or bad person, making ethical decisions that could impact the game as a whole. The game Bioshock gives players the opportunity to towards the greater good or towards a more devilish approach to the world. In a broad sense, this is akin to studying artwork from a variety of different cultures and backgrounds to gain insight into culture. Schrier's (2016) research offers the idea that playing video games could improve empathy in the real world. Zhang and Shang (2016) subscribe to the idea that controlling virtual avatars in video games is empowering for individuals to understand values and establish identities outside of the game. Controlling an avatar in a video game that is completely different from one's own identity could lead to a plethora of thoughts and reflections about identities.

\section{FUTURE RESEARCH}

Academic advisors should embrace a curiosity for knowledge including comparisons to other mediums such as video games. Like successful college students, advisors should examine the world from a curious lens, find connections between their field and influences, as well as learn about their own advising purpose (Bain, 2012). Making these connections between the field of advising and video games may seem farfetched 
at first but establishing these types of analytical connections can grow knowledge. Academic advisors are lifelong learners engaging in new ways of engaging with students. "Video games are a creative medium, and they offer us unparalleled opportunities for exploring what it means to be human" (Etchells, 2019, p. $\mathrm{X})$. At the very least, comparing video games and academic advising gives advisors an opportunity to reflect on how to be a successful advisor, learning ways to grow and allowing leeway for mistakes. Reflection is key for learning from video games. Connecting video games and academic advising is a starting point for examining how advising takes place and how each conversation is a unique opportunity to teach students.

\section{REFERENCES}

Bain, K. (2012). What the best college students do. Cambridge, Massachusetts: The Belknap Press of Harvard University Press.

Baldwin, A., Bunting, B., Daugherty, D., Lewis, L., \& Steenbergh, T. (2020). Promoting belonging, growth mindset, and resilience to foster student success. Columbia, SC: University of South Carolina, National Resource Center for First-Year Experience \& Students in Transition.

Bergonse, R. (2017). Fifty Years on, what exactly is a videogame? An essentialistic definitional approach. The Computer Games Journal, 6(4), 239-255.

Champlin-Scharff, P., \& Hagen, P. (2013). Understanding and interpretation: A hermeneutic approach to advising. In J. Drake, P. Jordan, \& M. Miller (Eds.), Academic advising approaches: Strategies that teach students to make the most of college (pp. 223-242). San-Francisco: Jossey-Bass.

Cooper, J. (Ed.). (1997). Plato: Complete works. Indianapolis: Hackett (Original work published in 399 BC by Plato).

Cote, A. (2020). Gaming sexism: Gender and identity in the era of casual video games. New York: NYU Press.

Csikszentmihalyi, M. (1997). Flow and the psychology of discovery and invention. New York: Harper Perennial.

Del Blanco, A., Torrente, J., Marchiori, E., Martínez-Ortiz, I., Moreno-Ger, P., \& Fernández-Manjón, B. (2012). A framework for simplifying educator tasks related to the integration of games in the learning flow. Educational Technology \& Society, 15(4), 305-318.

Dewey, J. (2005). Art as experience. New York: Perigree (Original work published in 1934).

Duggins, R. (2019). Innovation and problem solving teaching case: The breakout box-a desktop escape room. Journal of Organizational Psychology, 19(4), 73-77.

Eichenbaum, A., Bavelier, D., \& Green, S. (2014). Video games: Play that can do serious good. American Journal of Play, 7(1), 50-72.

Entertainment Software Association (ESA). (2020). 2020 essential facts about the video game industry. Retrieved from https://www.theesa.com/esa-research/2020-essential-facts-about-the-video-gameindustry/

Etchells, P. (2019). Lost in a good game. London: Icon Books Ltd.

Fleming, N. (2013, August). Why video games may be good for you. British Broadcasting Corporation (BBC). Retrieved from https://www.bbc.com/future/article/20130826-can-video-games-be-goodfor-you

Fraser, B. (2011). Why the spatial epistemology of the video game matters: Mētis, video game space and interdisciplinary theory. Journal of Gaming and Virtual Worlds, 3(2), 93-106.

Gee, E., \& Gee, J. (2017). Games as distributed teaching and learning systems. Teachers College Record, $119(12), 1-22$.

Gee, J. (2007). What video games have to teach us about learning and literacy. New York: Palgrave Macmillan.

Gentile, D., \& Groves, C. (2014). The general learning model: Unveiling the teaching potential of video games. In F. Blumberg (Ed.), Learning by playing: Video games in education (pp. 121-142). New York: Oxford University Press.

Granic, I., Lobel, A., \& Engels, R. (2014). The benefits of playing games. American Psychologist, 69(1), 66-78. 
Härig, D. (2012). Inside and outside the game. In J. Fromme \& A. Unger (Eds.), Computer games and the new media cultures: A handbook of digital game studies (pp. 209-217). New York: Springer.

Kimball, E., \& Campbell, S. (2013). Advising strategies to support student learning success: Linking theory and philosophy with intentional practice. In J. Drake, P. Jordan, \& M. Miller (Eds.), Academic advising approaches: Strategies that teach students to make the most of college (pp. 316). San-Francisco: Jossey-Bass.

Lowenstein, M. (2013). Envisioning the future. In J. Drake, P. Jordan, \& M. Miller (Eds.), Academic advising approaches: Strategies that teach students to make the most of college (pp. 243-258). San-Francisco: Jossey-Bass.

Lowenstein, M. (2020). If advising is teaching, what do advisors teach? NACADA Journal, 40(2), 5-14. (Original work published in 2005).

Mackay, R. (2013, March). Playing to learn: Panelists at Stanford discussion say using games as an educational tool provides opportunities for deeper learning. Stanford News. Retrieved from https://news.stanford.edu/2013/03/01/games-education-tool-030113/

McHaney, R. (2011). The new digital shoreline: How web 2.0 and millennials are revolutionizing higher education. Sterling, VA: Stylus Publishing.

McNamee, S. (2014). Some principles of good teaching. In D. Ashe \& C. Clements (Eds.), Best practices in university teaching (2nd edition, pp. 86-96). Wilmington, NC: Center for Teaching Excellence UNCW.

Montola, M. (2012). Social constructionism and ludology: Implications for the study of games. Simulation \& Gaming, 43(3), 300-320.

Mueleck, J., Smith, C., \& Allen, J. (2014). Understanding the advising learning process using learning taxonomies. NACADA Journal, 34(2), 63-74.

National Academic Advising Association (NACADA). (2021). Core Competencies. Retrieved from https://nacada.ksu.edu/Resources/Pillars/CoreCompetencies.aspx

Papert, S. (1998). Does easy do it? Children, games, and learning. Game Developer, 5(6), 88.

Przybylski, A., Weinstein, N., Murayama, K., Lynch, M., \& Ryan, R. (2012). The ideal self at play: The appeal of video games that let you be all you can be. Psychological Science, 23(1), 69-76.

Qian, M., \& Clark, K. (2016). Game-based learning and $21^{\text {st }}$ century skills: A review of recent research. Computers in Human Behavior, 63, 50-58.

Schrier, K. (2016). Emotion, empathy, and ethical thinking in Fable III. In S. Tettegah \& W. Huang (Eds.), Emotions, technology, and digital games (pp. 35-60). London: Academic Press/Elsevier.

Strayhorn, T. (2015). Reframing academic advising for student success: From advisor to cultural navigator. NACADA Journal, 35(1), 56-63.

Tannahill, N., Tissington, P., \& Senior, C. (2012). Video games and higher education: What can "Call of Duty" teach our students? Frontiers in Psychology, 3, 1-3.

Wiklund, M., \& Mozelius, P. (2013). Learning games or learning stimulating games: An indirect approach to learning stimulating effects from off-the-shelf games. International Journal of Digital Information and Wireless Communications, 3(3), 290-300.

Xyst, K. (2016). Constructionism, Dewey, and academic advising. NACADA Journal, 36(2), 11-19.

Ypsilanti, A., Vivas, A., Räisänen, T., Viitala, M., Ijäs, T., \& Ropes, D. (2014). Are serious video games something more than a game? A review on the effectiveness of serious games to facilitate intergenerational learning. Education and Information Technologies, 19, 515-529.

Zagal, J.P. (2008, November 3-5). A Framework for games literacy and understanding games. In Proceedings of Future Play 2008: Research, Play (pp. 33-40). Association for Computing Machinery.

Zhang, L., \& Shang, J. (2015) How video games enhance learning: A discussion of James Paul Gee's views in his book what video games have to teach us about learning and literacy. In S. Cheung, L. Kwok, H. Yang, J. Fong, \& R. Kwan (Eds), Hybrid learning: Innovation in educational practices ICHL 2015 (pp. 404-411). Springer. 